\title{
Variable Roll Stiffness System of An Automobile
}

\author{
Utsav Vyas \\ Mechanical Engineer, \\ Ahmedabad, India
}

\author{
Yash K. Shah \\ Mechanical Engineer, \\ Ahmedabad, India
}

\author{
Yash S. Shah \\ Mechanical Engineer, \\ Ahmedabad, India
}

\author{
Dishant Sojitra \\ Mechanical Engineer, \\ Ahmedabad, India
}

\begin{abstract}
In different road conditions every one's first priority is comfort as well as safety and there is a lot of importance of ride quality \& ease while travelling. The comfort of vehicle is directly linked with the level of safety offered during various road conditions. Road safety is one of the primary concern of each and every automobile driver. The anti-roll bar is an established feature of suspension design and is found on just about every modern day car - and plenty of classic cars too. In order to resist the car during the situation of extreme body roll Anti- Roll bar works as a link which stiffen the suspension to control this sort of action. Our objective is to develop a new active safety system for vehicles which controls the overall vehicle behavior in emergency situations. An adjustable anti-roll bar having a single set of mounting apertures whose roll stiffness can be adjusted at the middle of the Anti-Roll bar, in which variable roll stiffness is achieved by providing gear mechanism consisting of three mitre type bevel gears which is actuated by pneumatic means according to different road conditions. According to our design we are working in the area of vehicle dynamics in which our main focus is to provide variable roll stiffness at different road condition. Components which we will include for prototype building are 3 equal bevel gears, antiroll bar, pneumatic piston-plunger, suspensions. Pneumatic system is used which helps in providing flexibility to gear mechanism and hence improving the function of Anti- Roll bar.
\end{abstract}

Keywords \& component :- Road saftey, Anti-Roll Bar, Coil springs, Bevel gears, Single acting cylinder, 3/2 Direction control valve, Pump, Wheels, ECU, Roll stifness

\section{PROLEM DEFINATION}

Anti-Roll bar used in modern automobile cars serves the purpose of providing extra roll-stiffness during the condition of excessive cornering and makes the car less prone to extreme body roll. But while driving on highway, above mentioned function of Anti-Roll bar will result in improper ride with tyre frequently loosing contact with the road surface.According to the data provided by Indian government in a year of 2017 form total number of accidents $3,27,448$ are due to overspeeding of vehicle ${ }^{[1]}$.

\section{A. Why vehicle stability is required?}

There are many reasons for a vehicle to lose its controllability: unfavorable weather and road conditions, lack of regular vehicle care, maintenance and repair, the driver's inexperience, sharp cornering (when passing an obstacle or underestimating a curve). A vehicle will react in a different way when the driver steers smoothly, or when the vehicle slightly declines from the lane. Loss of stability of a vehicle may cause its skidding on the road.In above mention conditions for the safety and comfort of an automobile as well as driver, stability is the major concern which needs to be considered.

\section{INTRODUCTION}

Variable Roll Stiffness System of an Automobile is a system which provides varying roll stiffness, adequate stability as well as prevents the rolling of vehicle while excessive turning. By observing the current road scenario it becomes mandatory to understand vehicle behavior in accordance with respective road conditions. Imperative condition to co-relate the vehicle behavior with different road condition is that, vehicle stiffness must vary as per various road condition. Successful implementation of this system will decreases the chances of vehicle getting rolled over. This system includes anti-roll bar, pneumatic system, coil spring, electronic control unit, bevel gears, suspensions and wheel. Anti-roll bar is connected to the suspension strut. Anti-roll bar and suspension strut are interconnected through a ball jointed link. Combination of three mitre type bevel gear mechanism is placed in centered section of antiroll bar. Which provides opposite rotational motion relatively. We have double acting cylinder with $3 / 2 \mathrm{DCV}$ which controls engage and disengage of gear mechanism.Shape of anti-roll bars for automobile suspension systems are usually designed from a standpoint of avoiding physical interference with other components mounted on the bottom of a vehicle. Also the diameter of the bar is usually pre-selected and fixed to achieve a desired anti-roll stiffness. After having this much amount of constraints in shape and dimensions there is little design flexibility for engineers/designers. So in present invention we have configured the mechanism consisting of three mitre type bevel gears which can be engaged and disengaged. In engaged position of gears Anti-Roll bar will provide continuous traction while cornering, in disengaged position of gears it will flourish the riding comfort during uneven road conditions. 


\section{DESIGN \& CALCULATION}

\section{A. Design}

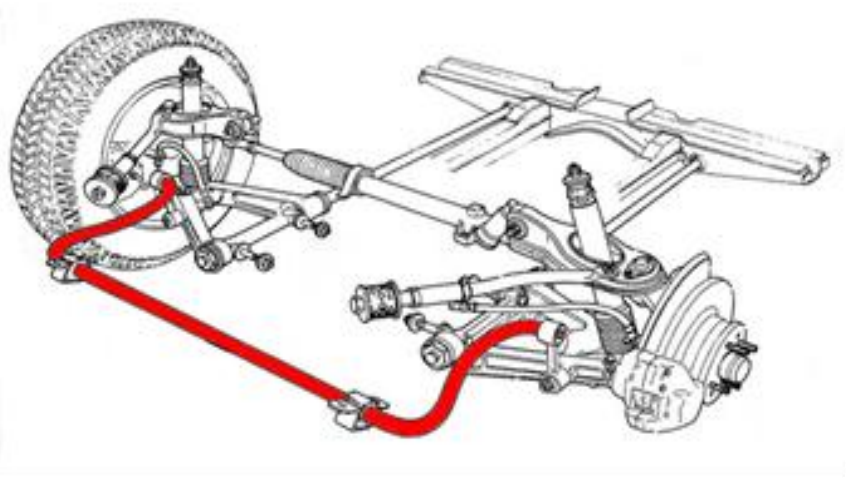

Fig. 1 Conventional Design of anti-roll bar ${ }^{[2]}$

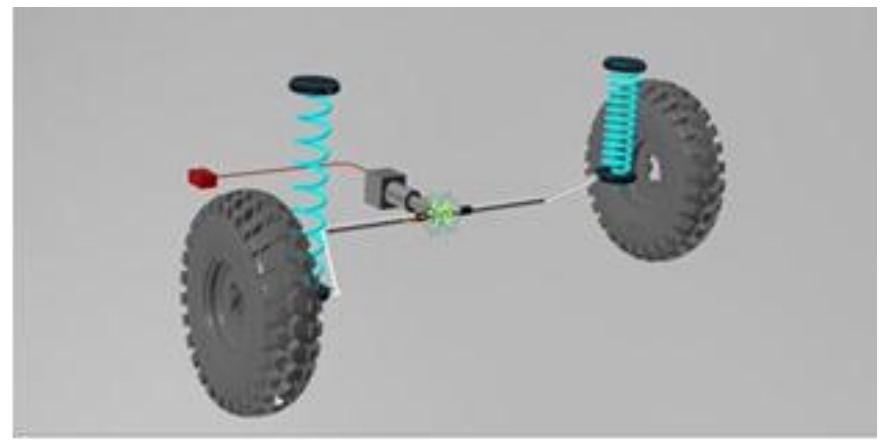

Fig. 2 Anti-roll bar designed in present invention

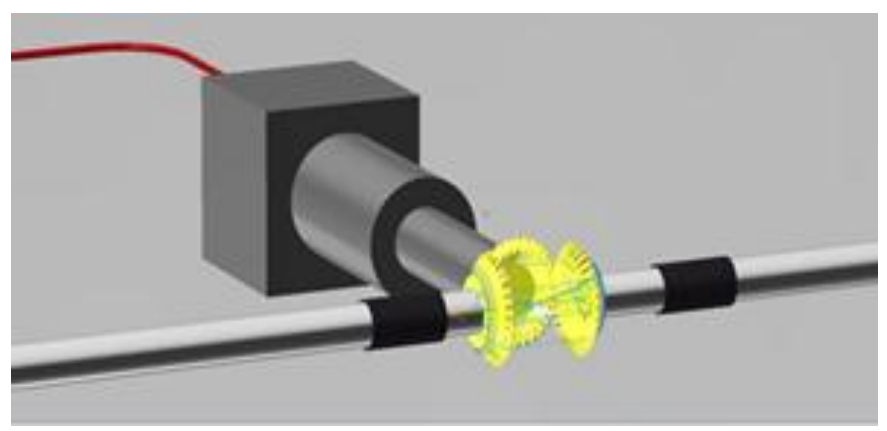

Fig. 3 Bevel gear mechanism

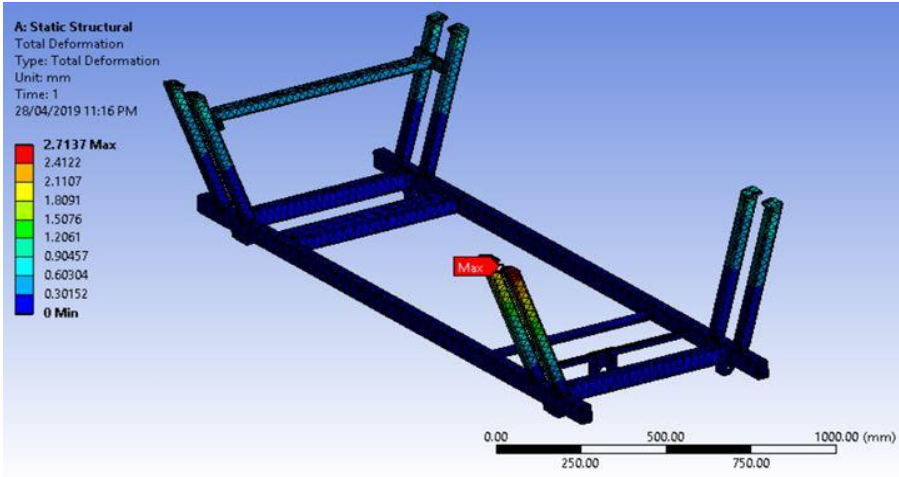

Fig. 4 Analysis of Chassis ( Total deformation)

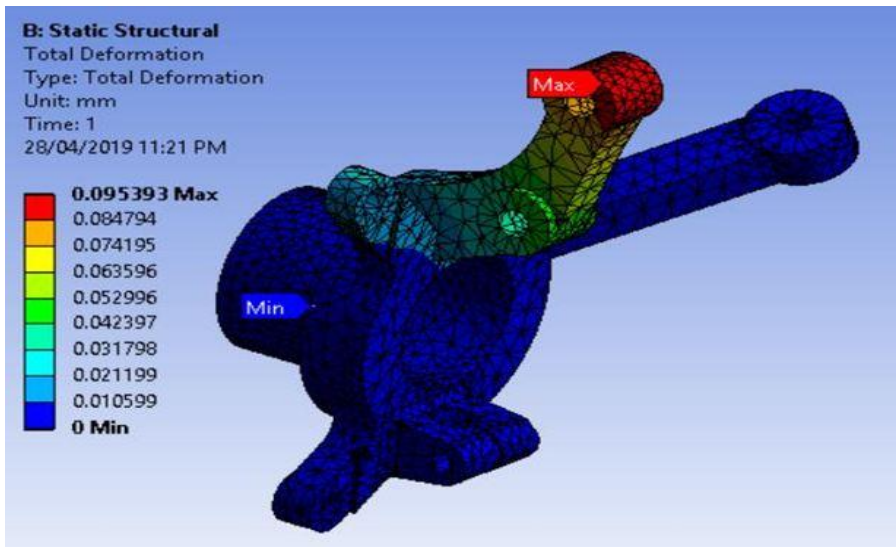

Fig. 5 Analysis of knuckle ( Total deformation)

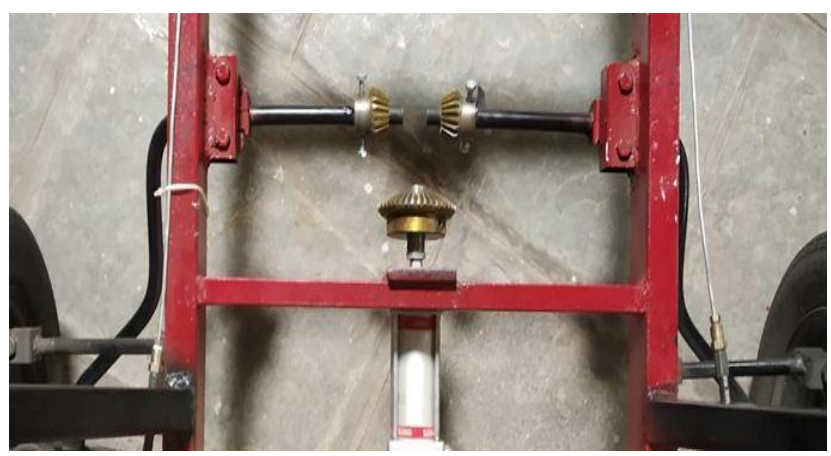

Fig. 6 Actual model 


\section{B. Calculation}

Designation of terms for Maruti $800^{[3]}$

Length $=3335 \mathrm{~mm}$

Width $=1440 \mathrm{~mm}$

Height $=1405 \mathrm{~mm}$

CG height $=500 \mathrm{~mm}$

Weight Distribution $=40: 60 \mathrm{~F}: \mathrm{R}$

Wheel Base $=2175 \mathrm{~mm}$, Track Width $=1295 \mathrm{~mm}$

Tyre Specification $=145 / 70 \mathrm{R} 12$

Ground Clearance $=170 \mathrm{~mm}$

PART 1:- Longitudinal weight transfer in an ideal car

longitudinal weight transfer $\left(\Delta W_{l}\right)$

$$
=\frac{\text { Acceleration } \times C G \text { height } \times \text { weight of the car }}{\text { wheelbase } \times 2}
$$

$\Delta W_{l}=\frac{1 \times 0.5 \times 650}{2.17 \times 2}=74.88 \mathrm{~kg}$

Vertical load on wheel $(C)=\left(\frac{650 \times 0.40}{2}+74.88\right)=130+74.88=204.88 \times 9.81$
$=2009.87 \mathrm{~N}$

$$
=2009.87 \mathrm{~N}
$$

Frictional Forces $(D)=0.8 \times 2009.87=1607.89 \mathrm{~N}$

Reaction Forces At Upright $(A \& B)=$ $\frac{2009.87 \times 0.8}{2}=803.94$

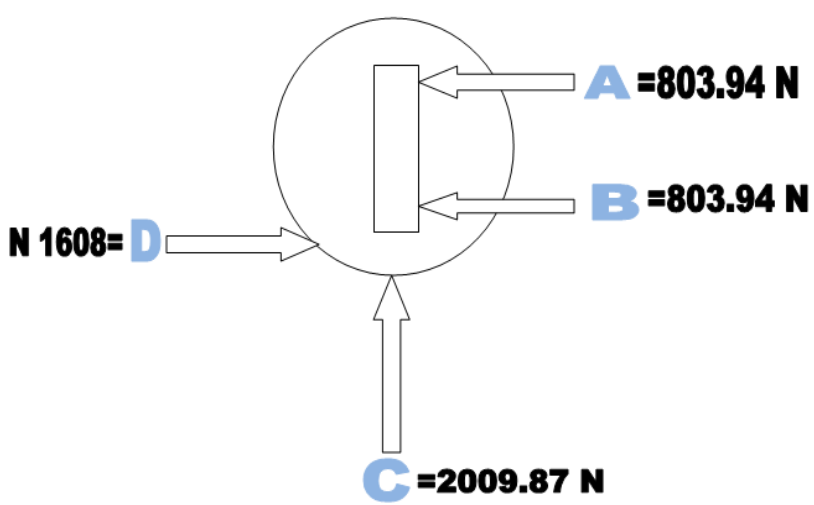

Fig. 7 Longitudinal weight transfer in an ideal car
PART 2 :- Transverse weight transfer in an ideal car

Transverse Weight transfer $=$

Acceleration $\times C G$ Weight $\times$ weight of the Car $\times \%$ weight distribution of the car Trackwidth $\times 9.81$

Lateral load transfer $\left(\Delta W_{t}\right)=$ $\frac{4 \times 0.5 \times 650 \times 0.40}{9.8 \times 1.295}=40.97 \mathrm{~kg}$

Vertical Load on vehicle while cornering $(A)=$ $(130+40.97) \times 9.8=1675.5 \mathrm{~N}$

Frictional Forces $(B)=1675.5 \times 0.8=$ $1340.4 \mathrm{~N}$

Moment about hub centre due to frictional force $=$ $1340.4 \mathrm{~N} \times 0.254=340.46 \mathrm{Nm}$

Force at point $C=\frac{340.46}{0.05}=6809.2 \mathrm{~N}$

Force at point $D=\frac{340.46}{0.13}=2618.9 \mathrm{~N}$

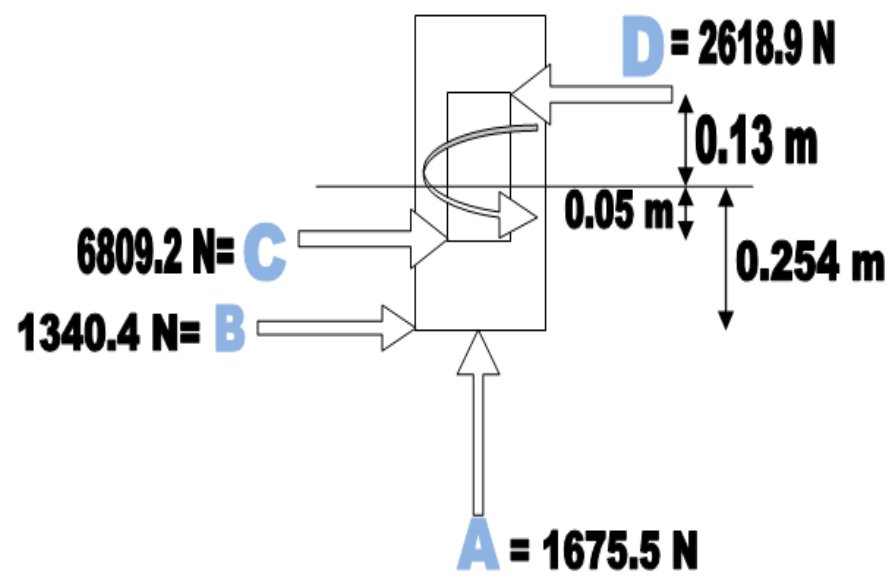

Fig. 8 Transverse weight transfer in an ideal car 


\section{$r=$ Bump radius (indian standards)}

Centrifugal force acting at a bump

$=\frac{m v^{2}}{r}=\frac{130 \times 12.5}{17}=1194.5 \mathrm{~N}$

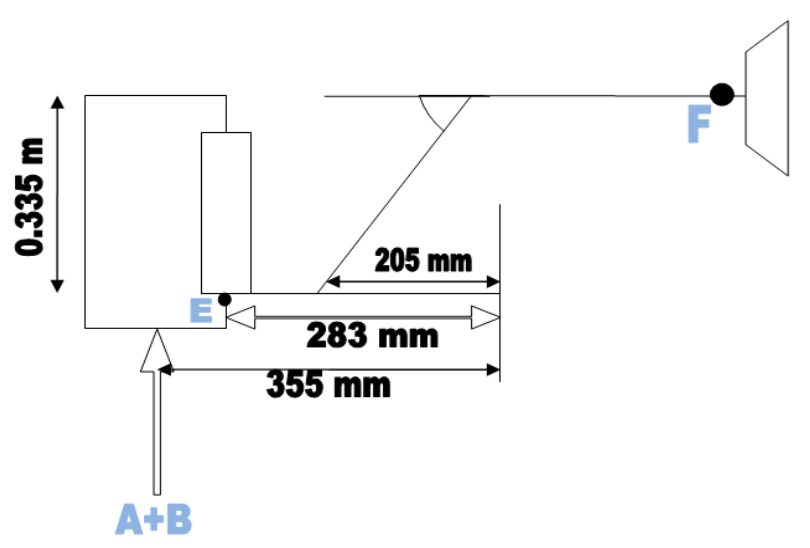

Fig. 9 Lateral load transfer considering Anti-roll bar

Consider only lateral load for Anti-Roll bar torque,

Vertical load on tyre $1675.5 \mathrm{~N}$

Forces at point $E=\frac{1675.5 \times 0.355}{0.283}=2101.8 \mathrm{~N}$

Torque at point $\mathrm{F}$ as an anti-roll bar,

$\tau=f \cdot r=2101.8 \times 0.335=704.103 \mathrm{Nm}$

if we consider that above mentioned longitudinal and transverse weight transfer are for condition of vehicle turning at right side then,

Now, consider a case of opposite side while on cornering for instance if vehicle is turning left, tyre reaction on right side is higher than left due to weight transfer.

we already have a value that is $\Delta W=40.97 \mathrm{~kg}$

Left side weight reactions are

$W_{l}=\frac{W}{2}-\Delta W=130-40.97=89.03 \times 9.81=$ $872.5 \mathrm{~N}$

Vertical load on left tire is $872.5 \mathrm{~N}$

Forces on point $\mathrm{E}=\frac{872.5 \times 0.355}{0.283}=1094.5 \mathrm{~N}$

Torque at point $\mathrm{F}$ as an anti-roll bar $\tau=f \cdot r=1094.5 \times 0.335=366.65 \mathrm{Nm}$

\section{PART:- 3 Calculation of Suspension Stiffness}

$k=\frac{d^{4} G}{8 D^{3}}$

$\mathrm{d}=$ Diameter of the spring wire $=9.5 \mathrm{~mm}$

$\mathrm{D}=$ Diameter of spring $=95 \mathrm{~mm}$

$\mathrm{G}=$ Shear modulus of spring material (ASTM A227) $=11600$ $\mathrm{GPa}$

$\mathrm{N}=$ Number of active coils $=5$

So, $k=\frac{(9.5)^{4} \times 11600}{8 \times 95^{3}}=25.816 \mathrm{~N} / \mathrm{mm}$

While in cornering to the left side, right side reactions will be high

so, force acting at knuckle point $=2101.8 \mathrm{~N}$

$F=k \cdot \delta x$

$\delta x=81.41 \mathrm{~mm}$

$\mathrm{F}=$ force in $\mathrm{N}$

$\mathrm{k}=$ Spring Stiffness

$\delta \mathrm{x}=$ Deflection of spring in $\mathrm{mm}$

Torque at right side mounted bevel gear

$\tau_{1}=704.103 \mathrm{Nm}$ (Clockwise)

Torque at left side mounted bevel gear $\tau_{2}=366.65 \mathrm{Nm}($ Anti - Clockwise $)$

Final (Clockwise rotation of) $\tau_{f}=337.453 \mathrm{Nm}$

$\tau_{f}=F \cdot r$

$f=\tau_{f} / r=1007.32 \mathrm{~N}$

$1007.32 \mathrm{~N}$ is a force at knuckle point $\mathrm{E}$

For finding tyre reaction at left tyre to the surface, force at point $\mathrm{E}$

$1007.32=\frac{x \times 0.355}{0.283}$

$x=\frac{1007.32 \times 0.283}{0.355}=803.02 \mathrm{~N}$

So, according to equation $F=k \cdot \delta x$

$\delta x=\frac{803.020}{25.816}=31.10 \mathrm{~mm}$ 
So, observing the results (1) \& (2)

we have conclude that during the situation of excessive cornering of a vehicle, we will get $31.10 \mathrm{~mm}$ of opposite deflection of tire in either side, when other tire is in compression or expansion of $81.41 \mathrm{~mm}$

PART 4:- Calculations of load acting on bevel gears

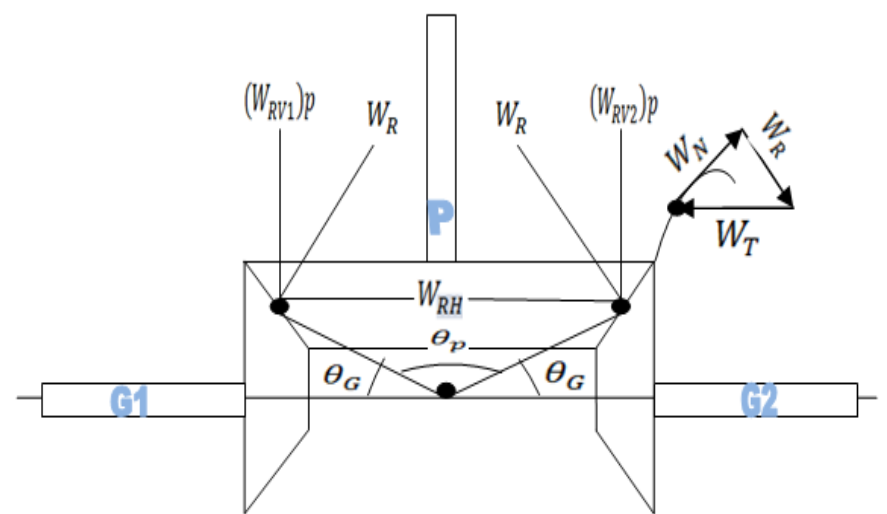

Fig.10 Forces acting on bevel gears

$\left(W_{R V 1}\right) p=$

Radial force acting on pinion shaft due to effect of gear G1

$\left(\mathrm{W}_{\mathrm{RV} 2}\right) p=$

Radial force acting on pinion shaft due to effect of gear G2

$\mathrm{W}_{\mathrm{RH}}=$ Axial force acting on pinion shaft

$\mathrm{Rm}=$ Mean radius of pinion

$\theta_{\mathrm{p}}=$ Pitch Angle for pinion
$\theta_{\mathrm{G}}=$ Pitch Angle for gear

Dp $=$ Pitch diameter of pinion

$\mathrm{DG}=$ pitch diameter of gear

$\mathrm{WT}=$ Tangential component of normal force

$\mathrm{WR}=$ Radial component of normal force

$\mathrm{WN}=$ Normal force

Dimension of bevel Gears :-

$$
\begin{aligned}
& \theta_{P}=\tan ^{-1}\left(\frac{1}{V \cdot R}\right)=\tan ^{-1}\left(\frac{1}{1 / 2}\right)=63.43^{\circ} \\
& \theta_{G}=\tan ^{-1}(V \cdot R)=\tan ^{-1}\left(\frac{1}{2}\right)=25.56^{\circ} \\
& D_{P}=m \times Z_{P}=2.5 \times 40=100 \mathrm{~mm} \\
& D_{G}=m \times Z_{G}=2.5 \times 20=50 \mathrm{~mm}
\end{aligned}
$$

Equivalent number of teeth

$$
\begin{aligned}
& Z_{E G}=Z_{G} \times \sec \left(\theta_{G}\right)=20 \times \\
& \sec \left(25.56^{\circ}\right)=22.17
\end{aligned}
$$

$Z_{E P}=Z_{P} \times \operatorname{Sec}\left(\theta_{P}\right)=20 \times$ $\sec \left(63.43^{\circ}\right)=89.42$

Cone Distane $(L)=\sqrt{\left(\frac{D_{P}^{2}}{2}\right)}+\sqrt{\frac{D_{G}^{2}}{2}}=$ $55.90 \mathrm{~mm}$

Mean Radius $(\mathrm{Rm})=\left(L-\frac{b}{2}\right) \frac{D_{P}}{2 L}=41.17 \mathrm{~mm}$

Face width $(B)=6.3 \mathrm{~m}$ to $9.5 \mathrm{~m}=19.75 \mathrm{~mm}$

Force acting on pinion

$\left(W_{t}\right)=\frac{T}{R_{m}}=\frac{704.13}{0.04117}=$

$17102.33 \mathrm{~N}$ (Left side)

$\left(W_{t}\right)=\frac{T}{R_{m}}=\frac{366.65}{0.04117}=$

$890.57 \mathrm{~N}$ (Right side)

Radial load acting on pinion from both side

$$
\begin{aligned}
& \left(W_{R V 1}\right)_{P}=W_{T} \cdot \tan \emptyset \cdot \cos \left(\theta_{P}\right)= \\
& 2784.9 N \\
& \left(W_{R V 2}\right)_{P}=W_{T} \cdot \tan \emptyset \cdot \cos \left(\theta_{P}\right)= \\
& 144.98 N \\
& \text { Total load on pinion }=\left(W_{R V 1}\right)_{P}+ \\
& \left(W_{R V 2}\right)_{P}=2784.9+144.98= \\
& 2929.24 N
\end{aligned}
$$

Module $=2.5$

Velocity Ratio = 1:2

$Z G=$ Number of teeth on gears $=20$

$\mathrm{ZP}=$ Number of teeth on pinions $=40$ 
According to our calculations if the vehicle is running at the speed of $100 \mathrm{kmph}$ then rear wheels will reach to speedbreaker within 0.08 seconds and our pneumatic system should take less time than this to retract and gears to be disengaged.

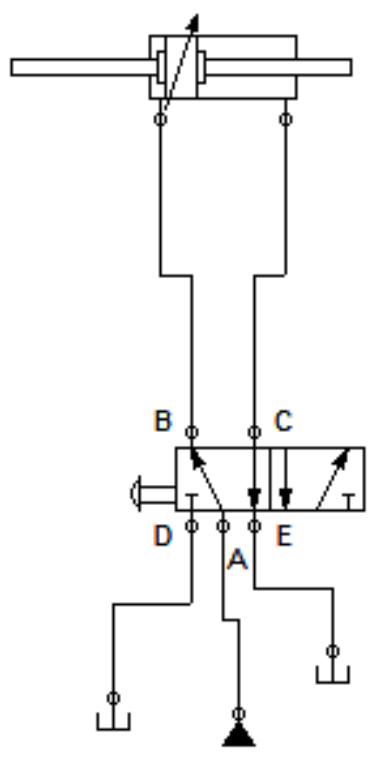

Fig.11 Pneumatic System Circuit Diagram

\section{PART:-5 Calculation of vehicle roll stiffness}

As we know that an either side suspension has a spring rate of $25.816 \mathrm{~N} / \mathrm{mm}$

so,

$$
\mathrm{k}=25.816 \mathrm{~N} / \mathrm{mm}
$$

Case-1 :- if the Anti-roll bar mechanism is in disengaged position means only suspension contributes to maintain the necessary stiffness

$$
K \emptyset s=\text { Roll stiffness of suspension }
$$

now in order to find out roll stiffness of a suspension we need to consider the torque( $\mathrm{T}$ ) acting to rotate the chassis about axis of roll,

$$
T=[(t / 2 * k L) \times t / 2)+(t / 2 * k R \times t / 2)] \theta
$$

Where, $k L=k R=$ individual wheel rates of left \& right tyre

$$
\mathrm{t}=\text { track-width in } \mathrm{mm}
$$

Now wheel rate, $=$ Angle correction factor $\times$ Spring rate $(k) \times(\text { Motion ratio })^{2}$

$k L=k R=\cos 8^{\circ} \times 25.816 \times(1) 2=25.567 \mathrm{~N} / \mathrm{mm}$.
Now, put the value of equation (2) in equation (1)

$\left.T=t^{2} / 4(k L+k R) \theta=\left((1.295)^{2} / 4\right) \times 0.02556\right) \theta$

$T / \theta=k_{\emptyset s}=0.0003741 \mathrm{~N} \cdot \mathrm{m} / \operatorname{degree} \cdots \cdots \cdots(a)$

Case-2:- If the Anti-roll bar mechanism is in engaged condition that means bar itself and suspensions act together as a unit to maintain required stiffness

we have to find out individual spring rate(stiffness) of an Antiroll bar which is designated as,

$k_{\mathrm{a}}($ lbs / inch $)$

$=500000 \times\left(O D^{4}-I D^{4}\right) /$

$\left(0.4244 \times A^{2} \times B\right)+\left(0.2264 \times C^{3}\right)=102.28($ lbs $/$ inch $)$

$=17.911 \mathrm{~N} / \mathrm{mm}$

$k_{\emptyset a}=$ Roll stiffness of Anti-roll bar

$k_{\emptyset a}=T / \theta$

$=\left(t^{2} \times \mathrm{k}_{\mathrm{a}}\right) /(2 \times 57.3)$

$=0.0002621(N \cdot m /$ degree $)$

Now following the addition of equation (a) \& (b) we will have total roll stiffness of a vehicle,

$\boldsymbol{k}_{\emptyset s_{+\mathrm{a}}}=\left[\boldsymbol{k}_{\emptyset \mathrm{s}}+\boldsymbol{k}_{\emptyset \mathrm{a}}\right]=0.0006362(\boldsymbol{N} \cdot \boldsymbol{m} /$ degree $)$

From case (1) \& (2) and from equation (a) \& (c) we have conclude that, our designed system can provide variableroll stiffness according to driver's need.

\section{CONCLUSION \& RESULT}

\section{A. Performance Parameters}

According to materials and design calculations, the outcome is that all the sub elements, even the smallest part being used should fulfill its purpose in accordance with its design. Our targeted design system is designed in such a way that it would not come direct contact with any road obstacle.

We have designed and manufactured our system in such a way that it can provide numerous features when implemented in automobile. While designing this system our primary focus is on providing variable roll stiffness to vehicle and this aim is fulfilled by manufacturing the system which can deliver extra roll stiffness to an automobile car. System is designed in such a way that it can help vehicle to enhance its load bearing capacity and safety during the conditions like excessive cornering. In addition to this, system also equipped with improved stability against lateral kerb strikes. 
The name of the system itself implies that it can deliver some excess amount of roll stiffness to vehicle. The arrangement of components and working efficiency of gear mechanism is maintained in a way that stiffness can be fluctuated according to various road conditions. For instance, while driving on a high way in order to take sharp turns as well as to achieve traction with road surface roll stiffness should be conserved at high rate but for off-road conditions where stiffness in not one of the concern then only disengagement of just one member from the mechanism will provide smoother ride.

After compilation of each and every component in a single unit, all of them are working in the system with our desired efficiency. This efficiency is achieved because of well-designed system, correct arithmetical calculation of each and every forces as well as dimensions, load analysis resulted by observing each and every possible load conditions. In addition to all of these appropriate material selection and carefully manufactured parts are also the reason behind successful implementation of the system.

There are some evaluated decisions which are taken on the bases of critical observation at each and every loose ends. Initially we have selected hydraulic system for the actuation of bevel gear mechanism but after following the market closely we have evaluated that pneumatic systems are more cheaper and quick in response, so we have selected pneumatic system to make bevel gear mechanism work. After learning from various reference books we understood that, means for compression of suspension at either side and having expansions on the other side Bevel gears are perfect choice. For ease of calculation and mounting feasibility mitre type bevel gears are best in use. In order to achieve the aim of variable roll stiffness we can also work in the area of suspensions but suspensions are one of the most critical part of the vehicle assembly, so according to constraint of cost effectiveness and ease of designing we have selected the Anti-Roll bar as a main component of the system. Basically we have implemented the technique of reverse engineering to achieve what we have thought.

\section{B. Conclusion}

By using different material with different dimensions we can design and manufacture such a system which can attach with any current automobile.

The final system as per our knowledge, research, study and discussion is that according to the current situations. The product should not be costly for its function and also that as a small and compact unit. Its endurance limit should be high and the design should be such that in future additional options, redesigning, additional features can be incorporated in the current design and this product should excel in its functions as cost, working, maintenance and feasibility.

\section{REFERENCES}

[1] https://morth.nic.in/road-accidents-india-2017

[2] Image via Evan Mason/Wikimedia, showing a front suspension setup with the anti-roll bar marked in red

[3] https://en.wikipedia.org/wiki/Maruti_800\#Dimensions_and_weights 